\title{
Blue 6-ps short-pulse generation in gain-switched InGaN vertical-cavity surface-emitting lasers via impulsive optical pumping
}

\section{$\operatorname{AUTHOR}(\mathrm{S}):$}

Chen, Shaoqiang; Okano, Makoto; Zhang, Baoping; Yoshita, Masahiro; Akiyama, Hidefumi; Kanemitsu, Yoshihiko

\section{CITATION:}

Chen, Shaogiang ... [et al]. Blue 6-ps short-pulse generation in gain-switched In GaN vertical-cavity surface-emitting lasers via impulsive optical pumping. Applied Physics Letters 2012, 101(19): 191108.

\section{ISSUE DATE:}

\section{2-11-07}

\section{URL:}

http://hdl.handle.net/2433/173932

\section{RIGHT:}

(C) 2012 American Institute of Physics 


\section{AIP Appinad physices Letters}

Blue 6-ps short-pulse generation in gain-switched InGaN vertical-cavity surface-emitting lasers via impulsive optical pumping

Shaoqiang Chen, Makoto Okano, Baoping Zhang, Masahiro Yoshita, Hidefumi Akiyama et al.

Citation: Appl. Phys. Lett. 101, 191108 (2012); doi: 10.1063/1.4766290

View online: http://dx.doi.org/10.1063/1.4766290

View Table of Contents: http://apl.aip.org/resource/1/APPLAB/v101/i19

Published by the American Institute of Physics.

Additional information on Appl. Phys. Lett.

Journal Homepage: http://apl.aip.org/

Journal Information: http://apl.aip.org/about/about_the_journal

Top downloads: http://apl.aip.org/features/most_downloaded

Information for Authors: http://apl.aip.org/authors

\section{ADVERTISEMENT}

\section{AIP | Applied Physics Letters}

Accepting Submissions in

Biophysics and Bio-Inspired Systems 


\title{
Blue 6-ps short-pulse generation in gain-switched InGaN vertical-cavity surface-emitting lasers via impulsive optical pumping
}

\author{
Shaoqiang Chen, ${ }^{1, a)}$ Makoto Okano, ${ }^{2}$ Baoping Zhang, ${ }^{3}$ Masahiro Yoshita, ${ }^{1}$ \\ Hidefumi Akiyama, ${ }^{1}$ and Yoshihiko Kanemitsu ${ }^{2}$ \\ ${ }^{1}$ Institute for Solid State Physics, University of Tokyo, 5-1-5 Kashiwanoha, Kashiwa, Chiba 277-8581, Japan \\ ${ }^{2}$ Institute for Chemical Research, Kyoto University, Uji, Kyoto 611-0011, Japan \\ ${ }^{3}$ Department of Physics, Xiamen University, Xiamen 361005, Fujian, China
}

(Received 20 August 2012; accepted 23 October 2012; published online 7 November 2012)

\begin{abstract}
We report the demonstration of the picosecond-pulse lasing in blue region from an optically pumped gain-switched InGaN vertical-cavity-surface-emitting laser (VCSEL). Through 150-fs optical pulse excitations at room temperature, multimode pulse lasing with a main mode at $436.5 \mathrm{~nm}$ from the InGaN VCSEL was observed. The output pulse widths were measured to be as short as $9.8 \mathrm{ps}$ for the total lasing spectra and $6.0 \mathrm{ps}$ for the main mode. Since the obtained short pulses were still not limited by its photon lifetime of $0.7 \mathrm{ps}$ or band-width of $0.8 \mathrm{~nm}$, possible ways to generate even shorter pulses have been examined. (C) 2012 American Institute of Physics. [http://dx.doi.org/10.1063/1.4766290]
\end{abstract}

Vertical-cavity surface-emitting lasers (VCSELs) have significant advantages such as single-longitudinal-mode operation, low laser threshold, circular output beam with low divergence, short cavity lifetime due to short cavity length, high intrinsic bandwidth, wafer-scale processing, and the capability to form two-dimensional device arrays. ${ }^{1-5}$ These advantages have made very attractive potential applications of VCSELs for compact light sources in high-speed optical communications, optical networks, and optical signal processing. Moreover, promising results have been reported regarding high-speed operation including picoseconds short pulses in optically pumped gain-switched GaAs and InGaAsP VCSELs, ${ }^{1-4}$ and high-speed modulation with a bandwidth of the order of $50-70 \mathrm{GHz}$ in electrically gainswitched InGaAs VCSELs. ${ }^{6,7}$

Owing to improvement of the crystal growth techniques for high-quality nitrides, nitride-based VCSELs with the lasing wavelength in blue and green regions have attracted increasing attention ${ }^{8-13}$ in fundamental research and application as on-demand optical sources in high-resolution laser printer and next generation of optical storages such as the high-density and high-capacity 3-dimensional optical storage. ${ }^{14,15}$ To decrease the device access time and improve the efficiency, optical pulse sources are preferred that have short pulse width, short delay time, and high peak power. Consequently, studying short-pulse generations in blue region is of great interest. So far, however, blue-short-pulse generations and the dynamics in nitride-based VCSELs have not yet been demonstrated, although the room-temperature steady-state lasing in blue region from $\mathrm{GaN}$ and $\mathrm{InGaN}$ VCSELs is established. ${ }^{8-13}$

In this paper, generation of 6.0-ps short pulses in 436.5-nm blue region from an InGaN VCSEL by gain switching was demonstrated. On the basis of the obtained pulse characteristics, possible ways to generate even shorter pulses have been discussed. Subpicosecond impulsive optical pumping was used here, to study physics of short-pulse generation by gain switch-

\footnotetext{
${ }^{\text {a) }}$ Author to whom correspondence should be addressed. Electronic mail: shaoqiangchen@gmail.com.
}

ing by avoiding the effects of the parasitic series resistances of the dielectric distributed-Bragg reflectors (DBRs) and the p-type layers in current injection.

The sample was fabricated by metal-organic chemical vapor deposition. The growth procedure was reported elsewhere. ${ }^{10,11}$ Figure 1 schematically shows the structure of the InGaN VCSEL. The sample consists of a $1.7-\mu \mathrm{m}$ bulk GaN layer, a 200-nm $\mathrm{Al}_{0.07} \mathrm{Ga}_{0.93} \mathrm{~N}$ cladding layer, an active region consisting of three sets of InGaN asymmetric quantum wells (with thicknesses of 2.5, 3.0, $3.5 \mathrm{~nm}$, respectively, aiming to obtain a low lasing threshold ${ }^{10}$ ) and $5-\mathrm{nm} \mathrm{GaN}$ spacer layers, a 115-nm GaN layer, a 150-nm $\mathrm{Al}_{0.07} \mathrm{Ga}_{0.93} \mathrm{~N}$ layer, and a 5-nm GaN cap layer. The DBRs deposited on both surfaces of the cavity are composed of 13.5 pairs of $\mathrm{Ta}_{2} \mathrm{O}_{5} / \mathrm{SiO}_{2}$ layers. Low-threshold steady-state lasing performance of the device was reported previously. ${ }^{10,11}$

The pulse lasing characteristics of the VCSEL were studied by fs impulsive optical excitation at $355 \mathrm{~nm}$ with a $0.5-\mathrm{mm}$ spot diameter. The 355-nm pulses were generated by the fourth harmonic of the signal output from an optical parametric amplifier (OPA) system pumped by 800 -nm pulses from a mode-locked Ti:sapphire regenerative amplifier (Spitfire, Spectra-Physics), operating at $150-\mathrm{fs}$ pulse duration and $1-\mathrm{kHz}$ repetition.

Blue output pulses of the VCSEL were characterized by using an optical Kerr-gate method, ${ }^{16-18}$ where the $800-\mathrm{nm}$ pulses partially split from the regenerative amplifier output controlled the on-off of the optical Kerr gate. The Kerr-gated and time-integrated spectra were measured by a spectrometer system with a liquid-nitrogen-cooled charge-coupled device. The temporal resolution of the Kerr gate was $0.7 \mathrm{ps}$ in the present system, which was mainly determined by the relaxation time of polarization in the Kerr medium (toluene). Time traces of amplified spontaneous emission (ASE) of the VCSEL below lasing threshold were characterized with a streak camera system with a temporal resolution of about 20 ps. To study steady-state lasing characteristics for reference, ns optical pumping was carried out at $355 \mathrm{~nm}, 25$-ns duration, and $30-\mathrm{kHz}$ repetition with the third-harmonics of a Q-switched $\mathrm{YVO}_{4}$ pulse laser. 


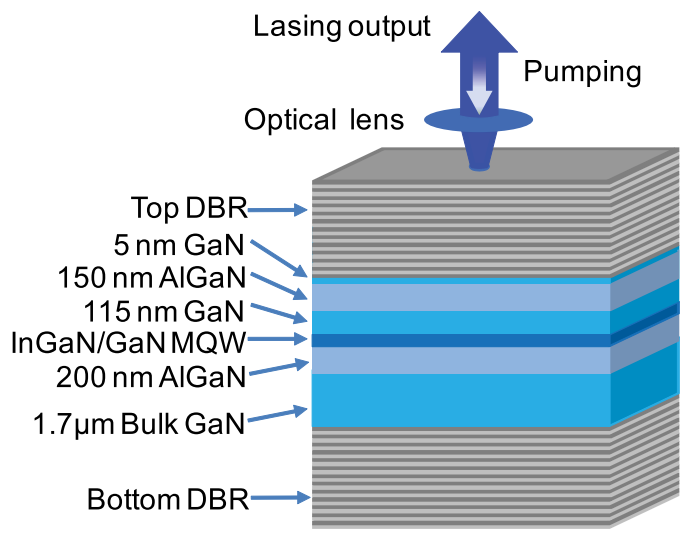

FIG. 1. Schematic of the structure of the InGaN VCSEL and the experiment configuration.

Figure 2(a) shows the time-integrated lasing spectrum of the VCSEL measured at a pumping energy of $500 \mathrm{~nJ} / \mathrm{pulse}$, which was 3.5 times higher than the threshold pumping energy $P_{\mathrm{th}}=140 \mathrm{~nJ} /$ pulse. A strong main lasing mode at $436.5 \mathrm{~nm}$, a sub mode at $439.8 \mathrm{~nm}$, and other weak modes at around $441 \mathrm{~nm}$ were observed. Figure 2(b) shows an ASE spectrum measured with the pumping energy of $60 \mathrm{~nJ} / \mathrm{pulse}$,

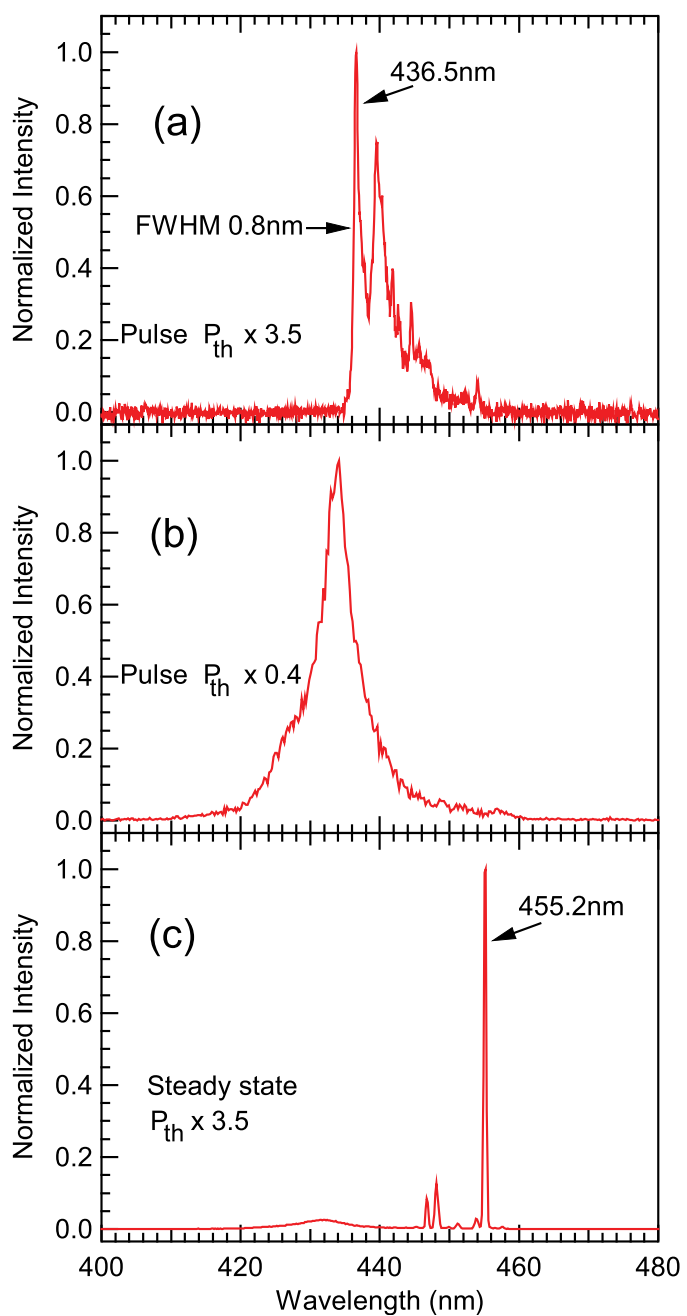

FIG. 2. Time-integrated spectra of the gain-switched VCSEL with (a) above-threshold subpicosecond pulse excitation, (b) below-threshold subpicosecond pulse excitation, and (c) above-threshold steady-state excitation. which was below the lasing threshold. Figure 2(c) shows a steady-state lasing spectrum measured under ns pumping at a level of 3.5 times above the threshold $P_{\text {th }}=0.74 \mu \mathrm{J} /$ pulse, where single mode lasing at a long wavelength of $455.2 \mathrm{~nm}$ is found.

The pulsed lasing occurred on the lower energy side of the ASE peak and showed blue-shifted multi-mode peaks unlike the steady-state lasing. Multi-mode peaks are possibly due to multiple transverse modes, ${ }^{19-21}$ caused by gain guiding, sample inhomogeneity, and/or localized states, even if the sample was designed as single longitudinal mode lasers. Further researches on the origins of multiple modes are in progress.

Figure 3(a) shows the pulse waveforms of the total lasing spectrum (dotted curve) and the main mode at $436.5 \mathrm{~nm}$ (solid curve). The output pulse width (full width at half maximum (FWHM)) of the total lasing spectrum from $430 \mathrm{~nm}$ to $460 \mathrm{~nm}$ was $9.8 \mathrm{ps}$. Figure 3(b) shows a measured decay curve (filled dots) of the ASE from the VCSEL below the lasing threshold corresponding to the spectrum in Fig. 2(b). A dashed curve shows the time trace of the pumping pulse, where the 19-ps width represents the temporal resolution of the streak camera. The ASE well below lasing threshold starts almost immediately with the pumping pulse and the decay of the ASE was single exponential with a decay time of $255 \mathrm{ps}$, as shown by a solid fitting curve. The rapid rise and the 255-ps long decay time of the ASE are very different with the 9.8 ps pulse width with a delay after the abovethreshold pumping as shown in Fig. 2(a). The stark contrast between these results clearly demonstrates that the $9.8 \mathrm{ps}$ short pulses in blue range were generated via gain-switching operation of an InGaN VCSEL.
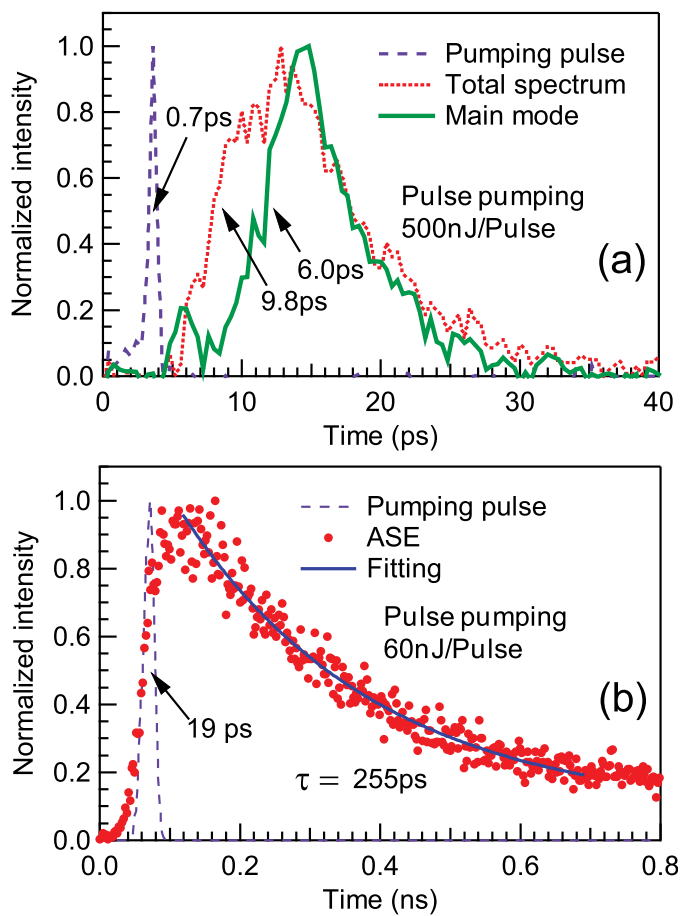

FIG. 3. (a) The waveforms of the total spectrum (dotted curve) and the main mode (solid curve) at $436.5 \mathrm{~nm}$. The $0.7 \mathrm{ps}$ response (dashed curve) of the pumping laser indicates the temporal resolution of the system. (b) Decay curve of the amplified spontanous emission with below-threshold subpicosecond pulse excitation. 
Note that the spectrally resolved waveform of the main mode at $436.5 \mathrm{~nm}$ shown by a solid curve in Fig. 3(a) was even shorter and had a FWHM of 6.0 ps. This indicates that 6.0-ps short pulses can be obtained by additionally using a narrowband-pass filter or by improving device structures to allow lasing in only a single mode.

We now examine the 6.0-ps pulse width obtained at $436.5 \mathrm{~nm}$. The $0.8-\mathrm{nm}$ (spectral resolution is $0.3 \mathrm{~nm}$ ) spectral width of the main mode provides a frequency bandwidth of $1.3 \mathrm{THz}$. This gives the time-bandwidth product of 7.6, which is far larger than the Fourier-transform-limited value of 0.44 (Gaussian) or $0.31\left(\mathrm{Sech}^{2}\right)$. This indicates that the obtained 6.0-ps pulses are strongly chirped, while they are generated via gain switching in a single mode. Such elongated pulses with strong chirping are inherent to gainswitched single-mode lasers, and could be further shortened by chirp compensation and spectral filtering. ${ }^{22}$

We next compare the 6.0-ps pulse width with the photon lifetime $\tau_{\mathrm{p}}$ of the present device, which is evaluated to be 0.7 ps according to the relationship $\tau_{\mathrm{p}}=\left(\mathrm{L} / \mathrm{v}_{\mathrm{g}}\right) / \ln (1 / \mathrm{R})$. Here, $\mathrm{v}_{\mathrm{g}}=1.0 \times 10^{-2} \mathrm{~cm} / \mathrm{ps}$ is the group velocity in VCSEL, $\mathrm{L}=2.3 \mu \mathrm{m}$ is the cavity length of the VCSEL, and R is the mean reflectivity of the DBR layers and estimated to be $97 \% .^{11}$ The photon lifetime of $0.7 \mathrm{ps}$ is shorter by a factor of eight than the obtained pulse width of 6.0 ps. Thus, the 6.0ps short pulse is not photon-lifetime limited.

In such cases, the gain-switched pulses should be further shortened, on the basis of our rate-equation analysis, ${ }^{23}$ by increasing optical gain; for example, by increasing quantumwell numbers and/or improving matching of quantum-well designs to VCSEL structures.

In conclusion, picosecond pulses in blue region were obtained at room temperature from a gain-switched InGaN VCSEL through 150-fs impulsive optical excitations. Using ultrafast time-resolved optical Kerr-gate measurements, multimode pulse lasing with a main mode at $436.5 \mathrm{~nm}$ was observed from the optically pumped InGaN VCSEL. The output pulse widths were measured to be as short as 9.8 ps for the total lasing spectra and $6.0 \mathrm{ps}$ for the main mode. Since the obtained short pulses were still neither photon-lifetime limited nor Fouriertransform limited, further studies by improving laser structure and/or using chirp compensation and spectral filtering should generate even shorter pulses by gain switching. The generation of picosecond pulses from the InGaN VCSEL demonstrated in this study is expected to pave the way for the applications of nitride-based VCSELs as short pulse blue light sources.
Part of this work was supported by the MEXT KAKENHI (Nos. 20104004 and 20104006), the Sumitomo Electric Industries Group CSR Foundation, and JST-CREST. One of the authors (S. Q. Chen) is thankful for the support of a JSPS fellowship (ID: P10374).

${ }^{1}$ L. G. Melcer, J. R. Karin, R. Nagarajan, and J. E. Bowers, IEEE J. Quantum Electron. 27, 1417 (1991).

${ }^{2}$ J. M. Wiesenfeld and J. Stone, IEEE J. Quantum Electron. 22, 119 (1986).

${ }^{3}$ M. A. Duguay, T. C. Damen, J. Stone, J. M. Wiesenfeld, and C. A. Burrus, Appl. Phys. Lett. 37, 369 (1980).

${ }^{4}$ J. R. Karin, L. G. Melcer, R. Nagarajan, J. E. Bowers, S. W. Corzine, P. A. Morton, R. S. Geels, and L. A. Coldren, Appl. Phys. Lett. 57, 963 (1990).

${ }^{5}$ C. J. Chang-Hasnain, J. P. Harbison, C. E. Zah, M. W. Maeda, L. T. Florez, N. G. Stoffel, and T. P. Lee, IEEE J. Quantum Electron. 27, 1368 (1991).

${ }^{6}$ D. Tauber, G. Wang, R. S. Geels, J. E. Bowers, and L. A. Coldren, Appl. Phys. Lett. 62, 325 (1993).

${ }^{7}$ G. Shtengel, H. Temkin, P. Brusenbach, T. Uchida, M. Kim, C. Parsons, W. E. Quinn, and S. E. Swirhun, IEEE Photon. Technol. Lett. 5, 1359 (1993).

${ }^{8}$ I. L. Krestnikov, W. V. Lundin, A. V. Sakharov, V. A. Semenov, A. S. Usikov, A. F. Tsatsul'nikov, Zh. I. Alferov, N. N. Ledentsov, A. Hoffmann, and D. Bimberg, Appl. Phys. Lett. 75, 1192 (1999).

${ }^{9}$ T. Someya, R. Werner, A. Forchel, M. Catalano, R. Cingolani, and Y. Arakawa, Science 285, 1905 (1999).

${ }^{10}$ J. Y. Zhang, L. E. Cai, B. P. Zhang, S. Q. Li, F. Lin, J. Z. Shang, D. X. Wang, K. C. Lin, J. Z. Yu, and Q. M. Wang, Appl. Phys. Lett. 93, 191118 (2008).

${ }^{11}$ J. Y. Zhang, L. E. Cai, B. P. Zhang, S. Q. Li, F. Lin, J. Z. Shang, D. X. Wang, K. C. Lin, J. Z. Yu, and Q. M. Wang, J. Lightwave Technol. 27, 55 (2009).

${ }^{12}$ J. T. Chu, T. C. Lu, M. You, B. J. Su, C. C. Kao, H. C. Kuo, and S. C. Wang, Appl. Phys. Lett. 89, 121112 (2006).

${ }^{13}$ T. C. Lu, C. C. Kao, H. C. Kuo, G. S. Huang, and S. C. Wang, Appl. Phys. Lett. 92, 141102 (2008).

${ }^{14}$ D. A. Parthenopoulos and P. M. Rentzepis, Science 245, 843 (1989).

${ }^{15}$ E. Walker, A. Dvornikov, K. Coblentz, and P. Rentzepis, Appl. Opt. 47, 4133 (2008).

${ }^{16}$ Y. Kanematsu, H. Ozawa, I. Tanaka, and S. Kinoshita, J. Lumin. 87-89, 917 (2000).

${ }^{17}$ T. Nagai, A. Yamamoto, and Y. Kanemitsu, Phys. Rev. B 71, 121201(R), (2005).

${ }^{18}$ J. Takeda, K. Nakajima, S. Kurita, S. Tomimoto, S. Saito, and T. Suemoto, Phys. Rev. B 62, 10083 (2000).

${ }^{19}$ C. J. Chang-Hasnain, M. Orenstein, A. Von Lehmen, L. T. Florez, J. P. Harbison, and N. G. Stoffel, Appl. Phys. Lett. 57, 218 (1990).

${ }^{20}$ C. J. Chang-Hasnain, J. P. Harbison, G. Harbison, A. C. Von Lehmen, L. T. Florez, and N. G. Stoffel, IEEE J. Quantum Electron. 27, 1402 (1991).

${ }^{21}$ S. Arafin, A. Bachmann, and M. C. Amann, IEEE J. Sel. Top. Quantum Electron. 17, 1576 (2011).

${ }^{22}$ S. Q. Chen, A. Sato, T. Ito, M. Yoshita, H. Akiyama, and H. Yokoyama, Opt. Express. 20, 24843 (2012).

${ }^{23}$ S. Q. Chen, M. Yoshita, T. Ito, T. Mochizuki, H. Akiyama, H. Yokoyama, K. Kamide, and T. Ogawa, Jpn. J. Appl. Phys., Part 1 51, 098001 (2012). 